MORAIS, Ricardo Manoel de Oliveira. Norma, gênero e representatividade: um estudo a partir do pensamento de Judith Butler. Revista Eletrônica Direito e Política, Programa de Pós-Graduação Stricto Sensu em Ciência Jurídica da UNIVALI, Itajaí, v.10, n.3, 2 quadrimestre de 2015. Disponível em: www.univali.br/direitoepolitica - ISSN 1980-7791

\title{
NORMA, GÊNERO E REPRESENTATIVIDADE: UM ESTUDO A PARTIR DO PENSAMENTO DE JUDITH BUTLER
}

\author{
NORM, GENDER AND REPRESENTATION: A STUDY FROM JUDITH \\ BUTLER'S THOUGHT
}

Ricardo Manoel de Oliveira Morais ${ }^{1}$

SUMÁRIO: Introdução; 1 O Problema do Sujeito, da Norma e da Verdade; 2 Gênero e Norma; 3 O Sujeito Constituído: Condição de Possibilidade para a Representatividade; Considerações Finais; Referências Das Fontes Citadas.

\section{RESUMO}

O artigo tem por objetivo compreender o gênero como norma a partir do pensamento de Judith Butler, valendo-se de um levantamento bibliográfico e de considerações teóricas acerca do tema. Para tanto, será examinada a noção de sujeito que, ao ser absolutizada, violenta certas singularidades que não se assujeitam a esta homogeneidade constituída. Tal noção de sujeito, ao assumir status de hegemonia, torna-se um paradigma que os indivíduos devem seguir, assujeitando-os por meio de práticas normalizadoras pautadas em discursos científicos. Neste sentido, o gênero será examinado como uma norma que gera uma série de práticas normalizadoras. Ainda, será investigado como as práticas normalizadoras funcionam como condição de possibilidade para que seja conferida representatividade a certos "sujeitos" homogeneamente definidos, cujo exterior permanece sem qualquer representação. Nas considerações finais, serão apontados alguns elementos relativos à resistência a este modelo normalizador instaurado pelos discursos de norma, partindo da proposta foucaultiana.

PALAVRAS-CHAVE: Gênero; Norma; Sujeito; Representatividade.

\section{ABSTRACT}

This article attempts to understand the gender as a norm from Judith Butler's

\footnotetext{
${ }^{1}$ Doutorando em Direito Político pela Universidade Federal de Minas Gerais sob a orientação da Professora Doutora Adriana Campos. Mestre em Filosofia Política pela Universidade Federal de Minas Gerais. Bacharel em Direito pela Faculdade Milton Campos. Bacharel em Filosofia pela Faculdade Jesuíta de Filosofia e Teologia. Advogado e professor Belo Horizonte, Minas Gerais, Brasil. Endereço eletrônico: ricardo_mom@hotmail.com.
} 
MORAIS, Ricardo Manoel de Oliveira. Norma, gênero e representatividade: um estudo a partir do pensamento de Judith Butler. Revista Eletrônica Direito e Política, Programa de Pós-Graduação Stricto Sensu em Ciência Jurídica da UNIVALI, Itajaí, v.10, n.3, 2ㅇ quadrimestre de 2015. Disponível em: www.univali.br/direitoepolitica - ISSN 1980-7791

thought, using the literature and the theoretical considerention about the subject. Therefore, it will exam the absolutization of the notion of subject that stretches the singularities that do not obligate to that composed homogeneity. That subject notion assumes a hegemony status, making itself the paradigm of the individuals, obligating them by normalizing practices based on scientific discourses. Thus, gender will be examined as norms that constitute normalizing practices. Finally, it will be shown how these normalizing practices operates as a condition of possibility for the representation of certain "subjects", homogeneously defined, whose outside remains without any representation. In the final considerations, it will be appointed some details of the resistance to this normalizing model established by speeches of norm, from Foucault's proposal.

KEY-WORDS: Gender; Norma; Subject; Representation.

\section{INTRODUÇÃO}

Este artigo tem por objetivo compreender o problema do gênero enquanto norma, partindo do pensamento de Judith Butler, problematizando a noção de "sujeito" e das instituições políticas que se pautam nesta noção. Primeiramente serão evidenciadas algumas reflexões acerca da noção de sujeito, conhecimento e verdade. Em seguida, será examinado o caráter de veridicção presente nas normas e nas práticas normalizadoras, evidenciando que a absolutização de determinada noção de sujeito e de verdade produz "dissidentes", que serão submetidos a práticas homogeneizantes, repressivas e produtivas. Partindo desta crítica, pretende-se explicitar o fato de que a representatividade se pauta, justamente, em subjetivação e assujeitamento do normalizado, o que implica que há, neste modelo, um "lado de fora" não representável, sujeitado pelas práticas normalizadoras.

Tais reflexões terão como ponto de partida Problemas de gênero, de Butler, bem como seu artigo Regulações de Gênero. Além disso, serão utilizados alguns apontamentos de Michel Foucault (que a própria Butler problematiza), sobretudo a questão da norma e das práticas de assujeitamento, em Os anormais, História da sexualidade I: A vontade de saber e Leçons sur la volonté de savoir. 
MORAIS, Ricardo Manoel de Oliveira. Norma, gênero e representatividade: um estudo a partir do pensamento de Judith Butler. Revista Eletrônica Direito e Política, Programa de Pós-Graduação Stricto Sensu em Ciência Jurídica da UNIVALI, Itajaí, v.10, n.3, 2ㅇ quadrimestre de 2015. Disponível em: www.univali.br/direitoepolitica - ISSN 1980-7791

Vale ressaltar que o título de Problemas de gênero é bem sugestivo. Conforme Butler destaca na introdução, o termo "problema", segundo o senso comum, é justamente aquilo que se deve evitar. A rebeldia e sua repressão em potencial dá lugar a uma operação extremamente sutil de poder: se a lei "dominante" ameaça com eventuais "problemas", para que se evite este tipo de situação indesejada, deve-se evitar problemas. Todavia, sua proposta é justamente criar um campo no qual seja possível criar problemas, canalizando-os para uma crítica da noção de gênero e do modo como discursos naturalizantes sobre sexo são empregados por técnicas científicas ou sociais de normalização, por vezes violentas (dentre as quais as cirurgias "corretivas" de sexo de crianças intersexuais) ${ }^{2}$.

Assim, ao colocar em evidência a artificialidade destes discursos e práticas empregados nas normas de gênero, será examinada a questão da produção de sujeitos pelas instituições políticas representativas. Se, por um lado, para que se consiga a representação, é necessário que seja constituído um campo subjetivo dotado de características pretensamente homogêneas, passíveis de serem representadas politicamente, por outro, todas as outras singularidades que não se encaixam nestas características homogêneas e necessárias à representação não serão representadas, mas assujeitadas e violentadas em sua singularidade pelas práticas normalizadoras.

\section{O PROBLEMA DO SUJEITO, DA NORMA E DA VERDADE}

A tradição metafísica sustenta a existência de um sujeito absoluto, compreendido a partir de uma concepção essencialista. Este sujeito, pela via do racional e do universal inteligível, acessaria a verdade e poderia, de forma absoluta, chegar a um saber atemporal e essencial. Entretanto, Foucault e Butler problematizam esta noção de sujeito como uma instância capaz de definir essências atemporais, criticando as noções de verdade e racionalidade preexistentes, independentes e definidoras das instituições e práticas sociais (e não o contrário).

\footnotetext{
${ }^{2}$ BUTLER, Judith. Problemas de gênero: feminismo e subversão de identidade. Tradução de Renato Aguiar. Rio de Janeiro: Civilização Brasileira, 2003. P.9.
} 
MORAIS, Ricardo Manoel de Oliveira. Norma, gênero e representatividade: um estudo a partir do pensamento de Judith Butler. Revista Eletrônica Direito e Política, Programa de Pós-Graduação Stricto Sensu em Ciência Jurídica da UNIVALI, Itajaí, v.10, n.3, 2ㅇ quadrimestre de 2015. Disponível em: www.univali.br/direitoepolitica - ISSN 1980-7791

Nesta perspectiva, a proposta é pensar a realidade nos termos de uma genealogia, colocando em xeque o estatuto universal da verdade como entidade transcendente. Foucault, em Leçons sur la volonté de savoir ${ }^{3}$, propõe, a partir do pensamento de Nietzsche, pensar o conhecimento e os absolutos como dimensões arbitrárias, fruto não da superioridade racional do homem diante da natureza, mas assumindo que o conhecimento não passa de uma presunçosa invenção, fruto de um "instinto" de dominação e poder, "vontade de potência".

Foucault investiga uma série de teorias do sujeito e processos de constituição de verdades que, ao se formarem a partir de práticas sociais, encampam certos conteúdos e marginalizam outros. Isso ocorre não devido a um progresso do saber humano, mas devido a mudanças de paradigma de diferentes racionalidades, cujo conjunto de crenças, situados fora da onipotência racional, propicia efeitos de verdade decorrentes de redes institucionais e processos de veridicção emergidos nas relações de poder.

Vale, ainda que de forma esquemática, esclarecer alguns elementos acerca da analítica das relações de poder. Primeiramente, não se deve analisar o poder segundo a perspectiva do legalismo ou da legitimidade, mas apreendê-lo em suas extremidades, onde ele se consolida em práticas de intervenção local, inclusive violentas.

Além disso, não é apropriado analisar o poder sob a ótica da decisão, de quem o detém, mas levar em consideração as intenções internas às práticas sociais, observando seus efeitos externos, não teóricos. Igualmente, não se deve observar porque as pessoas querem dominar ou o que elas buscam, mas o que ocorre no momento da sujeição e de seus processos perpétuos, que dirigem gestos e comportamentos.

Em terceiro lugar, não se deve conceber o poder como efeito de dominação linear ou piramidal, de um sobre os demais, pois poder não é algo que se detém ou cede, mas que circula, flui, opera em cadeia. O poder se constitui em práticas

${ }^{3}$ FOUCAULT, Michel. Leçons sur la volonté de savoir. Édition établie sous la direction de François Ewald et Alessandro Fontana, par Daniel Defert. Seuil/Gallimard: 2011. 
MORAIS, Ricardo Manoel de Oliveira. Norma, gênero e representatividade: um estudo a partir do pensamento de Judith Butler. Revista Eletrônica Direito e Política, Programa de Pós-Graduação Stricto Sensu em Ciência Jurídica da UNIVALI, Itajaí, v.10, n.3, 2ㅇ quadrimestre de 2015. Disponível em: www.univali.br/direitoepolitica - ISSN 1980-7791

e relações, sendo todos alvos e protagonistas, o que não significa que ele é bem distribuído, que parte do centro e se prolonga até os elementos atomísticos da sociedade. Assim, o poder deve ser analisado de forma ascendente, partindo dos mecanismos infinitesimais, que possuem sua própria história, trajetória, técnicas e táticas, sendo, em seguida, observado como esses mecanismos de poder possuem sua solidez e tecnologia próprias.

Por fim, é necessário se ter claro que não são as ideologias que sustentam as bases das redes de poder em seus pontos capilares, ainda que grandes máquinas de poder sejam acompanhadas de produções ideológicas, mas são relações que estão para além disso, tais como as práticas normalizadoras ${ }^{4}$.

Cesar Candiotto, em Foucault e a crítica da verdade, examina este sujeito universal como fundamento de verdade e fonte absoluta de significação, mostrando que tanto os discursos de verdade quanto o que se entende por sujeito, são constituídos por jogos de poder, estratégias e práticas sociais. A realidade não deve ser analisada a partir de um pressuposto metafísico, pois este tipo de análise oculta minúcias e singularidades do campo social e político ${ }^{5}$.

Uma análise mais acertada deve ser genealógica, avaliando os acontecimentos como corpo do devir, mantendo os fatos ocorridos em sua dispersão, demarcando acidentes, erros e falhas. Preconiza-se uma história descontínua, não como uma "teoria", mas como analítica que compreende o fundo de poder na máscara da verdade. Em última instância, a genealogia visa compreender o fundo das relações de poder, aquilo que a absolutização do sujeito tentou ocultar 6 .

Neste sentido, a verdade pode ser considerada uma instância que se rearranja conforme dominações, constituindo-se em práticas, sendo possível constatar na

\footnotetext{
${ }^{4}$ FOUCAULT, Michel. Em Defesa da Sociedade. Tradução de Maria Ermantina Galvão. São Paulo: Martins Fontes, 1999.

${ }^{5}$ CANDIOTTO, Cesar. Foucault e a crítica da verdade. Belo Horizonte: Autêntica Editora; Curitiba: Champagnat, 2010.

${ }^{6}$ CANDIOTTO, Cesar. Foucault e a crítica da verdade. Belo Horizonte: Autêntica Editora; Curitiba: Champagnat, 2010.
} 
MORAIS, Ricardo Manoel de Oliveira. Norma, gênero e representatividade: um estudo a partir do pensamento de Judith Butler. Revista Eletrônica Direito e Política, Programa de Pós-Graduação Stricto Sensu em Ciência Jurídica da UNIVALI, Itajaí, v.10, n.3, 2ㅇ quadrimestre de 2015. Disponível em: www.univali.br/direitoepolitica - ISSN 1980-7791

sociedade os locais onde elas se manifestam e arrogam para si o caráter de absoluto, gerando efeitos de verdade e aparência de universalidade. Vale ressaltar que a verdade não passa de artificialidade, que se instaura sob um emaranhado de relações de poder. Para que o conhecimento tenha tal aparência, deve violentar a realidade, forçando uma ordenação frente ao inordenável .

Esta tentativa de de ordenar pelo conhecimento, estabelecendo verdades e práticas metafísicas, por contrariar e violentar a dimensão da singularidade da existência, não deve ser concebida como se fosse idealizada e materializada por um sujeito ou uma classe pensante, perversa ou interessada. A constituição do sujeito se dá nas próprias práticas e instituições, de forma caótica, cuja apropriação propiciará a certo segmento uma situação de hegemonia.

(...) inexiste qualquer sujeito de verdade que determine sua compreensão e as constitua como tais, pelo contrário, tratase de situar a constituição do sujeito a partir daquilo que se faz com ele num determinado momento, na condição de louco, doente, criminoso, dirigido etc. As práticas deixam de ser comandadas somente pelas instituições, prescritas pelas ideologias ou guiadas pelas circunstâncias; elas têm regularidades próprias, estratégias e tecnologias específicas, racionalidades peculiares ${ }^{8}$.

Tendo em vista que o sujeito, para Foucault e Butler, é uma unidade superficialmente constituída, bem como as verdades ordenadoras, cabe esclarecer que, para que estas tentativas ordenadoras (e normalizadoras) consigam respaldo (como com o gênero por exemplo), devem gerar efeitos de verdade, não simplesmente nos termos de uma lei (jurídica) meramente repressiva, mas que produzem. Castro expõe que norma e lei, por mais que possam coexistir, não podem ser concebidas como sinônimas. Se, por um lado, a lei, numa acepção jurídica, remete a uma noção de restrição, de um ordenamento codificado ou sistematizado que qualifica determinadas condutas

\footnotetext{
${ }^{7}$ FOUCAULT, Michel. Leçons sur la volonté de savoir. Édition établie sous la direction de François Ewald et Alessandro Fontana, par Daniel Defert. Seuil/Gallimard: 2011.a

${ }^{8}$ CANDIOTTO, Cesar. Foucault e a crítica da verdade. p. 19.
} 
MORAIS, Ricardo Manoel de Oliveira. Norma, gênero e representatividade: um estudo a partir do pensamento de Judith Butler. Revista Eletrônica Direito e Política, Programa de Pós-Graduação Stricto Sensu em Ciência Jurídica da UNIVALI, Itajaí, v.10, n.3, 2ㅇ quadrimestre de 2015. Disponível em: www.univali.br/direitoepolitica - ISSN 1980-7791

como permitidas ou proibidas, a norma estabelece um campo de comparação, uma média de condutas a serem seguidas ${ }^{9}$.

A norma, a partir da valorização das condutas, impõe uma conformidade a se alcançar, homogeneizando, traçando a fronteira do anormal e uma série de procedimentos "regulamentares" para este "anormal"10. Ewald salienta que:

(...) a norma não se opõe à lei, mas àquilo que fez da lei um modo de expressão de um poder ligado à ideia de soberania: o 'jurídico' (...). Ao jurídico que caracteriza o direito da monarquia opõe-se (...) o normativo, encontrando este um meio particular de se exprimir em constituições, em códigos $(\ldots)^{11}$.

Butler, em Regulações de gênero, evidencia, acerca da relação entre norma e gênero, que

\begin{abstract}
À primeira vista, o termo "regulação" parece sugerir a institucionalização do processo pelo qual as pessoas são tornadas normais. De fato, referir-se à regulação no plural já é reconhecer que são essas leis, regras e políticas concretas que constituem os instrumentos legais pelos quais as pessoas são tornadas normais. Mas seria um equívoco, creio eu, compreender todas as maneiras pelas quais gênero é regulado em termos dessas instâncias legais empíricas, porque as normas que governam essas regulações superam as próprias instâncias nas quais são corporificadas. Contudo, seria igualmente problemático falar sobre regulações de gênero em abstrato, como se as instâncias empíricas apenas exemplificassem operações de poder que ocorrem de maneira independente delas próprias ${ }^{12}$.
\end{abstract}

Pode-se dizer que muitos estudos do gênero como norma concentram-se nas regulações existentes, leis jurídicas, militares, psiquiátricas, etc. Ou seja, existe uma gama de análises das verdades já estabelecidas sobre o gênero, mas sem

${ }^{9}$ CASTRO, Edgardo. Vocabulário de Foucault: um percurso pelos seus temas, conceitos e autores. Tradução de Ingrid Müller Xavier. Belo Horizonte: Autêntica Editora, 2009.

${ }^{10}$ CASTRO, Edgardo. Vocabulário de Foucault: um percurso pelos seus temas, conceitos e autores. Tradução de Ingrid Müller Xavier. Belo Horizonte: Autêntica Editora, 2009. p.309.

${ }^{11}$ EWALD, François. Foucault a norma e o direito. Tradução de Antônio Fernando Cascais. Lisboa: Veja, 1993. p.78.

12 BUTLER, Judith. Regulações de gênero. Cadernos Pagu, n 42, Campinas Jan./June 2014. Disponível em: http://www.scielo.br/scielo.php?pid=S010483332014000100249\&script=sci_arttext\&tlng=es\#fn01. Acesso em 6 de junho de 2015. Sem página. 
MORAIS, Ricardo Manoel de Oliveira. Norma, gênero e representatividade: um estudo a partir do pensamento de Judith Butler. Revista Eletrônica Direito e Política, Programa de Pós-Graduação Stricto Sensu em Ciência Jurídica da UNIVALI, Itajaí, v.10, n.3, 2ㅇ quadrimestre de 2015. Disponível em: www.univali.br/direitoepolitica - ISSN 1980-7791

problematizar esta questão genealogicamente, que é a proposta da Butler. Se, por um lado, estes estudos centram-se no modo como o gênero é regulado, como as regulações são impostas, aceitas ou incorporadas, por outro, não basta simplesmente que o gênero seja definido como repressão de uma força exterior. Ao analisar os procedimentos normalizadores, não parece plausível que tenha sempre existido um gênero ontológico, preexistente ao sujeito, sendo o papel das regulações simplesmente moldar os sexos a esta forma transcendente.

Butler lembra as advertências foucaultianas sobre a sujeição normativa: 1) o poder normalizador não age apenas sobre o sujeito ou um gênero pré-existente, mas delimita e forma esse sujeito; toda forma jurídica de poder possui efeito de produção; "(...) (2) tornar-se sujeito de uma regulação equivale a ser assujeitado por ela, ou seja, tornar-se sujeito precisamente porque foi regulado"13 $^{13}$. Logo, não se trata de analisar os regulamentos como variantes acidentais da norma essencial, buscando o "em si" normativo, mas de evidenciar os processos que levam à constituição das normas e o quão artificiais eles são ${ }^{14}$. Por mais que hajam mecanismos normativos de legitimação e produção, se eles forem genealogicamente descortinados, as normas irão mostrar-se superficiais ${ }^{15}$.

Butler questiona Foucault acerca do gênero e sua relação com a norma. Se para Foucault o gênero é uma modalidade normativa dentro de um grande sistema de poder normalizador, Butler parece conferir à norma do gênero uma maior atenção. Por mais que tipos particulares de regulamentações de gênero possam ser compreendidos como exemplos de um conjunto saberes normalizadores, definir a norma de gênero apenas como um exemplo específico desta máquina é, para Butler, questionável.

Pois, se a sabedoria de Foucault parece consistir na percepção de que o poder regulador possui certas características históricas amplas que influenciam tanto 0 gênero quanto outros tipos de normas sociais e culturais, isso equivale a dizer que gênero é apenas parte de uma

\footnotetext{
${ }^{13}$ BUTLER, Judith. Regulações de gênero. Sem Página.

${ }^{14}$ Cf. FONSECA, Márcio Alves. Michel Foucault e o Direito. São Paulo: Max Limonad, 2002.

${ }^{15}$ BUTLER, Judith. Regulações de gênero. Sem Página.
} 
MORAIS, Ricardo Manoel de Oliveira. Norma, gênero e representatividade: um estudo a partir do pensamento de Judith Butler. Revista Eletrônica Direito e Política, Programa de Pós-Graduação Stricto Sensu em Ciência Jurídica da UNIVALI, Itajaí, v.10, n.3, 2ㅇ quadrimestre de 2015. Disponível em: www.univali.br/direitoepolitica - ISSN 1980-7791

operação reguladora de poder mais ampla. Gostaria de argumentar, contra essa subsunção do gênero ao poder regulador, que o aparato regulador que governa o gênero é ele próprio generificado. Com isso não quero dizer que a regulação de gênero é paradigmática das relações de poder enquanto tais, mas sim que gênero requer $e$ institui seu próprio regime regulador e disciplinar específico ${ }^{16}$.

Em outras palavras, o gênero é uma norma, não uma instância ou um campo de manifestação e incidência de outras normas. Evidente que tais formulações não são excludentes, mas a proposta de trabalhar o gênero como norma implica, em grande medida, em problematizar esta questão como um dispositivo autônomo a ser desemaranhado ${ }^{17}$.

As normas, de um modo geral, podem ser separadas, analiticamente, do conjunto de processos no qual se inserem, ou seja, um procedimento normalizador de uma singularidade pode ser, artificialmente, analisado em separado da norma que o legitima. Mas, ainda que "(...) práticas sociais sob o padrão implícito da normalização" tenham esta possibilidade de análise separada, a norma "(...) também pode mostrar-se recalcitrante a quaisquer esforços de descontextualizarão de sua operação"18. Uma norma, ao operar em procedimentos e práticas ligadas a um princípio normalizador, normalmente permanece implícita, agindo de forma sutil, refindada e dificilmente perceptível.

Para que o gênero seja analisado como norma, deve ser compreendido como algo tenuemente incorporado num dispositivo gerador de efeitos de verdade. Se

\footnotetext{
${ }^{16}$ BUTLER, Judith. Regulações de gênero. Sem Página.

17 Deleuze descreve o dispositivo como um novelo ou um conjunto multilinear, um complexo composto por "linhas" de distintas naturezas, incapazes de delimitar sistemas de poder como homogêneos por conta própria, que seguem diferentes direções, fazendo emergir processos desequilibrados, nos quais as linhas se aproximam e afastam umas das outras. Tais linhas estão quebradas e submetidas a variações de direção e derivação, e os objetos visíveis, enunciações formuláveis, forças em exercício, sujeitos numa determinada posição são como vetores e tensores nessa rede. Assim, grandes instâncias saber-poder-subjetividade que Foucault distingue não possuem contornos definitivos, sendo espécies de cadeias de variáveis relacionadas entre si. Desemaranhar linhas de um dispositivo ou fazer uma genealogia é como traçar um mapa, percorrendo terras desconhecidas, razão pela qual não se pode contentar apenas em compor as linhas de um dispositivo, mas atravessá-lo, tentando estender ao máximo suas linhas (DELEUZE, Gilles. Qu'est-ce qu'un dispositive?. In. Michel Foucault philosophe: Rencontre international. Paris 9, 10, II janvier 1988. Seuil/Gallimard, 1989. p.15).
}

${ }^{18}$ BUTLER, Judith. Regulações de gênero. Sem Página. 
MORAIS, Ricardo Manoel de Oliveira. Norma, gênero e representatividade: um estudo a partir do pensamento de Judith Butler. Revista Eletrônica Direito e Política, Programa de Pós-Graduação Stricto Sensu em Ciência Jurídica da UNIVALI, Itajaí, v.10, n.3, 2ㅇ quadrimestre de 2015. Disponível em: www.univali.br/direitoepolitica - ISSN 1980-7791

Foucault, em Os anormais, evidencia o conjunto de práticas jurídicas, judiciárias médicas que compõe este elemento gerador de efeitos de verdade acerca da constituição do criminoso ${ }^{19}$, Butler propõe analisar os elementos responsáveis por esta dimensão no que tange ao gênero.

\section{GÊNERO E NORMA}

Uma vez que o sujeito não é um dado, mas é constituído, bem como suas práticas, pautadas em paradigmas geradores de efeitos verdades que se manifestam com status de conhecimento, Butler sustenta que:

Para que o gênero seja uma norma, isso sugere que ele esteja sempre e apenas tenuamente incorporado num ator social específico. A norma governa a inteligibilidade social da ação, mas não é o mesmo que a ação que ela governa. A norma parece ser indiferente às ações que ela governa, e com isso quero dizer apenas que a norma aparenta ter um estatuto e efeito independente das ações governadas por ela. A norma governa inteligibilidades, permitindo que determinadas práticas e ações sejam reconhecidas como tais, impondo uma grelha de legibilidade sobre o social e definindo os parâmetros do que será e do que não será reconhecido como domínio do social. A questão acerca do que estará excluído da norma estabelece um paradoxo, pois se a norma confere inteligibilidade ao campo social e normatiza esse campo para nós, então estar fora da norma é continuar, em certo sentido, a ser definido em relação a ela. Não ser totalmente masculino ou não ser totalmente feminina é continuar sendo entendido exclusivamente em termos de uma relação a "totalmente masculino" e "totalmente feminina"20.

Nesta perspectiva, sustentar o gênero como norma não é restringi-lo a uma visão dualista (legalista) de feminino e masculino. Ainda que tal perspectiva da norma exista, o gênero não é algo do campo do "ser" (ontológico ou determinista) ou do "ter", mas a forma como se age discursivamente num

\footnotetext{
${ }^{19}$ FOUCAULT, Michel. Os anormais. Tradução de Eduardo Brandão. São Paulo: Martins Fontes, 2001.

${ }^{20}$ BUTLER, Judith. Regulações de gênero. Sem Página.
} 
MORAIS, Ricardo Manoel de Oliveira. Norma, gênero e representatividade: um estudo a partir do pensamento de Judith Butler. Revista Eletrônica Direito e Política, Programa de Pós-Graduação Stricto Sensu em Ciência Jurídica da UNIVALI, Itajaí, v.10, n.3, 2ㅇ quadrimestre de 2015. Disponível em: www.univali.br/direitoepolitica - ISSN 1980-7791

processo normativo. Pode-se dizer que o gênero é um dispositivo de produção e normalização do indivíduo, seja ele masculino, feminino, etc., que se manifesta em formas intersticiais, hormonais, cromossômicas, físicas e performativas.

Analisar o gênero como uma realidade biológica que somente se manifesta no sexo (com certas "variáveis"),

(...) é perder de vista o ponto crítico de que essa produção coerente e binária é contingente, que ela teve um custo, e que as permutações de gênero que não se encaixam nesse binarismo são tanto parte do gênero quanto seu exemplo mais normativo ${ }^{21}$.

Assimilar o gênero em sua expressão normativa é, simplesmente, reconsolidar de forma inadvertida todos os efeitos de verdade gerados pelas relações de poder que tentam definir o gênero. Da mesma forma que "gênero" pode ser analisado como um mecanismo por meio do qual o "masculino" e o "feminino" são produzidas e naturalizadas, pode, igualmente, ser concebido como um dispositivo cuja genealogia descontrai e desnaturaliza estes binarismos.

Deve-se pensar o gênero como um dispositivo não determinado pelo sexo, pois "A assimilação entre gênero e masculino/feminina, homem/mulher, macho/fêmea, atua assim para manter a naturalização que a noção de gênero pretende contestar"22. Butler, em Problemas de gênero, explica que há uma ontologia indiscutida nesta distinção entre sexo e gênero que, embora concebida originalmente para colocar em cheque a biologia como destino, ainda universaliza a noção de sexo como um dado biológico, definindo o gênero como mera construção cultural ${ }^{23}$.

Entretanto o gênero não é resultado causal do sexo, tampouco fixo. Na medida em que o status de gênero como radicalmente distinto do sexo é questionado, o próprio sexo se torna um artifício flutuante, pois homem e masculino podem,

\footnotetext{
${ }^{21}$ BUTLER, Judith. Regulações de gênero. Sem Página.

22 BUTLER, Judith. Regulações de gênero. Sem Página.

${ }^{23}$ BUTLER, Judith. Problemas de gênero: feminismo e subversão de identidade. Tradução de Renato Aguiar. Rio de Janeiro: Civilização Brasileira, 2003.
} 
MORAIS, Ricardo Manoel de Oliveira. Norma, gênero e representatividade: um estudo a partir do pensamento de Judith Butler. Revista Eletrônica Direito e Política, Programa de Pós-Graduação Stricto Sensu em Ciência Jurídica da UNIVALI, Itajaí, v.10, n.3, 2ㅇ quadrimestre de 2015. Disponível em: www.univali.br/direitoepolitica - ISSN 1980-7791

facilmente, designar tanto um corpo feminino quanto um masculino, bem como mulher e feminino, um corpo masculino ou feminino. Uma crítica genealógica deve colocar em xeque discursos que estabelecem estas "verdades normalizadoras" da cisão gênero/sexo, pois

(...) um discurso restritivo sobre gênero que insista no binarismo homem e mulher como a maneira exclusiva de entender o campo do gênero atua no sentido de efetuar uma operação reguladora de poder que naturaliza a instância hegemônica e exclui a possibilidade de pensar sua disrupção ${ }^{24}$.

Tendo em vista que o próprio caráter imutável do sexo pode ser questionado, talvez a construção denominada "sexo" seja tão culturalmente constituída como gênero: "(...) talvez o sexo sempre tenha sido o gênero, de tal forma que a distinção entre sexo e gênero revela-se absolutamente nenhuma"25, justamente devido ao fato de um "corpo masculino" poder designar o "feminino" ou o "masculino" e vice-versa. Nessa perspectiva, sendo o sexo uma categoria tomada em seu gênero, não há qualquer fundamento em definir o gênero como mera interpretação cultural do sexo. Logo, gênero não deve ser entendido como inscrição cultural de um significado biológico de sexo previamente dado, o que nada mais seria que uma interpretação repressiva da realidade normativa.

Vale dizer que não se trata de colocar a questão do gênero como norma para reforçar os processos de normalização, perguntando, por exemplo, quantos gêneros podem existir, como nomeá-los ou regulá-los. A disrupção do sistema binário normalizador não necessita de levar ao questionamento o número de gêneros, de forma a constituí-los como sujeitos normalizados e juridicamente inscritos. Analisar o gênero como norma não deve levar à constituição de novas normas acerca das singularidades, na medida em que o poder normalizador, ao estabelecer novos campos de inteligibilidade subjetivos, apenas reforçará as normas existentes.

\footnotetext{
${ }^{24}$ BUTLER, Judith. Regulações de gênero. Sem Página.

${ }^{25}$ BUTLER, Judith. Problemas de gênero: feminismo e subversão de identidade. p. 25.
} 
MORAIS, Ricardo Manoel de Oliveira. Norma, gênero e representatividade: um estudo a partir do pensamento de Judith Butler. Revista Eletrônica Direito e Política, Programa de Pós-Graduação Stricto Sensu em Ciência Jurídica da UNIVALI, Itajaí, v.10, n.3, 2ㅇ quadrimestre de 2015. Disponível em: www.univali.br/direitoepolitica - ISSN 1980-7791

Isso sugere não apenas que a relação entre práticas e a idealização a partir das quais ela funciona é contingente, mas também que a própria idealização pode ser questionada e problematizada, potencialmente desidealizada e desinvestida ${ }^{26}$.

A distância entre gênero e norma é naturalmente concretizada nesta mesma distância aparente entre a norma e suas incorporações regulamentares, legais. Conforme sugerido, ainda que a norma possa ser analiticamente estudada independente de suas incorporações, isso se dá apenas como "exercício intelectual", na medida em que tal perspectiva corrobora a perpetuação da norma como atemporal e inalterável.

Ainda que certas normas persistam no tempo, sendo atualizadas e reinstituídas ao longo de inúmeros ritos de constituição de verdades por práticas, isso não deve reforçar a aparência de "ser" da norma.

A norma não possui um estatuto ontológico independente, mas não pode ser facilmente reduzida a sua concretização; ela própria é (re)produzida na sua corporificação, por meio dos atos que se esforçam para se aproximar dela, por meio de idealizações reproduzidas nos e por esses atos ${ }^{27}$.

Neste sentido pode-se, inclusive, pensar um paralelo entre Butler e Foucault. Foucault evidenciou justamente o fato de que a emergência de um determinado dispositivo normativo como um modo de regulação social não é idêntico às operações legais e repressivas dos sistemas de poder. Assim, por mais que o refinamento e a ampliação dos procedimentos normativos judiciários, legais, médicos, levem a uma inflação legislativa, norma e lei não se confundem ${ }^{28}$.

Tendo o poder normativo encampado dispositivos de verdade de modo a estabelecer normas e procedimentos com status científico (como a loucura, que é definida pela psiquiatria, constatada judicialmente por um perito, decretada por um juiz e tratada por especialistas por procedimentos normalizadores), as práticas jurídicas foram amplamente utilizadas neste movimento, fazendo com

\footnotetext{
${ }^{26}$ BUTLER, Judith. Regulações de gênero. Sem página.

${ }^{27}$ BUTLER, Judith. Regulações de gênero. Sem página.

${ }^{28}$ EWALD, François. Foucault a norma e o direito. p.79.
} 
MORAIS, Ricardo Manoel de Oliveira. Norma, gênero e representatividade: um estudo a partir do pensamento de Judith Butler. Revista Eletrônica Direito e Política, Programa de Pós-Graduação Stricto Sensu em Ciência Jurídica da UNIVALI, Itajaí, v.10, n.3, 2ㅇ quadrimestre de 2015. Disponível em: www.univali.br/direitoepolitica - ISSN 1980-7791

que certas leis passassem a ser veículos de normas e procedimentos normalizadores

Segundo Nancy Fraser, Foucault analisa a questão da justificação epistêmica dada à norma e seus procedimentos. O autor, ao não tratar das práticas normalizadoras segundo sua verdade ou falsidade, mas analisando como se inseriram historicamente e como determinam os efeitos de verdade nos regimes de saber na circunscrição judiciária, evidencia o modo como o poder normativo torna-se uma instância de poder altamente presente na sociedade moderna ${ }^{29}$. Foucault, em sua genealogia da norma, evidencia o modo como os discursos normativos vão paulatinamente invadindo as discursividades científicas, levando a certas situações (denunciadas por Bulter) de absolutização do binarismo sexual ${ }^{30}$.

Vale apenas ressaltar que o raciocínio normativo vigorava antes da modernidade, mas ele somente será encampado pelos saberes científicos na modernidade, tornando-se a medida verdadeira constituída pelas ciências (psicologia, medicina), culminando na instituição de processos normalizadores. Ewald expõe que "(...) a sua referência [da norma] já não é o esquadro, mas a média; a norma toma agora o seu valor de jogo das oposições [cientificamente constituídas] entre o normal e o anormal ou entre o normal e o patológico" ${ }^{31}$.

Ewald argumenta que o início do século XIX instaurou uma alteração radical nas relações entre a regra e a norma, e que a norma emerge conceitualmente não apenas como uma variação particular das regras, mas também como uma maneira de produzir as regras, e como um princípio de valoração ${ }^{32}$.

\footnotetext{
${ }^{29}$ FRASER, Nancy. Foucault on Modern Power: Empirical Insights and Normative Confusions. In. SMART, Berry (org.). Michel Foucault: Critical Assessments. Londres e Nova Iorque: Routledge, 1995.

${ }^{30}$ FOUCAULT, Michel. Os anormais. Tradução de Eduardo Brandão. São Paulo: Martins Fontes, 2001.

${ }^{31}$ EWALD, François. Foucault a norma e o direito. p.79.

32 BUTLER, Judith. Regulações de gênero. Sem Página.
} 
MORAIS, Ricardo Manoel de Oliveira. Norma, gênero e representatividade: um estudo a partir do pensamento de Judith Butler. Revista Eletrônica Direito e Política, Programa de Pós-Graduação Stricto Sensu em Ciência Jurídica da UNIVALI, Itajaí, v.10, n.3, 2ㅇ quadrimestre de 2015. Disponível em: www.univali.br/direitoepolitica - ISSN 1980-7791

Macherey explica que as práticas normativas a sociedade na qual os indivíduos constituem-se como sujeitos, apontando a contingência destas práticas de assujeitamento $^{33}$. Stéphane Legrand, em Les normes chez Foucault, também neste sentido, ao tratar da questão do poder normalizador, evita considerá-lo como poder homogêneo, analisando as normas não como uma potência supra individual, mas como uma realidade que se articula no interior de dispositivos, efeitos de verdade e regimes normativos diversos. Trata-se, seguindo a perspectiva de Foucault, de demonstrar as condições de possibilidade para a articulação dos diferentes códigos normativos, tomados como equivalentes gerais, quase transcendentes, mas que, de fato, são historicamente determinados e emergem contingentemente ${ }^{34}$. Assim, levando-se em consideração esta contingência, o objetivo é demonstrar como

(...) a norma transforma constrangimentos num mecanismo, e assim marca o movimento pelo qual, em termos foucaultianos, o poder jurídico torna-se produtivo; ela transforma as restrições negativas do jurídico nos controles mais positivos da normatização; assim, a norma desempenha essa função transformadora. A norma assim marca e causa a mudança entre pensar o poder como limitação jurídica para pensar o poder como (a) um conjunto organizado de restrições e $(b)$ um mecanismo regulador ${ }^{35}$.

Não se trata de pensar a norma em termos de uma abstração normativa que se materializa em processos localizados. A norma, sendo um meio de se produzir um padrão comum por processos regulamentares, forma sujeitos "normais" a partir desta média. Todavia, o anormal não possui uma natureza diferente do normal. A norma, na medida em que se formula num campo de relações de poder, não reconhece um "exterior", integrando tudo aquilo que aparentemente está para além dela. Nada ou ninguém, por mais diferente que seja, pode alegar exterioridade do campo normativo ${ }^{36}$.

\footnotetext{
33 MACHEREY, Pierre. De Canguilhem à Foucault: la force des normes. Paris: La Fabrique éditions, 2009.

34 LEGRAND, Stéphane, Les normes chez Foucault. Paris: Presses universitaires de France, 2007.

35 BUTLER, Judith. Regulações de gênero. Sem página.

${ }^{36}$ BUTLER, Judith. Regulações de gênero. Sem página.
} 
MORAIS, Ricardo Manoel de Oliveira. Norma, gênero e representatividade: um estudo a partir do pensamento de Judith Butler. Revista Eletrônica Direito e Política, Programa de Pós-Graduação Stricto Sensu em Ciência Jurídica da UNIVALI, Itajaí, v.10, n.3, 2ㅇ quadrimestre de 2015. Disponível em: www.univali.br/direitoepolitica - ISSN 1980-7791

Pensar a norma em termos de imanência é, em grande medida, não considerá-la sob uma perspectiva restritiva. Desta forma, quando se pensa que a norma transcende seus procedimentos, é uma forma de "desimanentizar" a análise da norma. Esta análise é

(...) formulada em termos da interdição exercida contra um sujeito dado, anteriormente à performance da sua ação, sugerindo assim que esse sujeito poderia, por si próprio, liberar-se ou ser liberado desse tipo de controle $(\ldots)^{37}$.

Este tipo de libertação da norma, na verdade, a reforça. Aqueles que lutam pela inserção na normalidade acabam por conseguir tal condição ou não. Caso consigam, eles reforçam a norma, na medida em que alcançam a condição de sujeito, mas excluindo todos aqueles que não caibam nesta definição.

Neste sentido, "A norma confere realidade ativamente; de fato, somente pela virtude de seu poder repetido de conferir realidade, é que a norma é constituída como uma norma" ${ }^{38}$. Na medida em que as pessoas são reguladas por gênero, este tipo de regulação não somente reprime, mas opera como uma condição de inteligibilidade. Caso haja um "desvio da norma de gênero", a produção da realidade do "aberrante" é um exemplo de dispositivo normativo que os procedimentos normalizadores de gênero (médicos, psiquiatras) podem criar para efetivar a racionalidade da norma.

A questão da "correção" cirúrgica de crianças intersexuais é um exemplo disso. Sob o argumento "científico" de que essas crianças nascem com características sexuais irregulares, devendo adequar-se à normalidade, tais cirurgias corretivas são realizadas a graves custos psíquicos e físicos, na medida em que produzem corpos por meio de uma execução reguladora do gênero marcada por dor e violência.

Gênero é assim uma norma reguladora, mas é também uma das regulações produzidas a serviço de outras formas de regulações. Por exemplo, os códigos de assédio sexual

\footnotetext{
37 BUTLER, Judith. Regulações de gênero. Sem página.

38 BUTLER, Judith. Regulações de gênero. Sem página.
} 
MORAIS, Ricardo Manoel de Oliveira. Norma, gênero e representatividade: um estudo a partir do pensamento de Judith Butler. Revista Eletrônica Direito e Política, Programa de Pós-Graduação Stricto Sensu em Ciência Jurídica da UNIVALI, Itajaí, v.10, n.3, 2ㅇ quadrimestre de 2015. Disponível em: www.univali.br/direitoepolitica - ISSN 1980-7791

tendem a supor que, seguindo as razões apresentadas por Catharine MacKinnon, 0 assédio consiste na sistemática subordinação sexual da mulher no local de trabalho, estando o homem geralmente na posição de quem assedia, e a mulher, de assediada. Para Mackinnon, isso parece ser consequência de uma subordinação sexual mais fundamental da mulher. Embora essas regulações procurem limitar tal comportamento humilhante no ambiente de trabalho, elas também carregam consigo certas normas tácitas de gênero. Em certo sentido, a implícita regulação de gênero parte da regulação explícita da sexualidade ${ }^{39}$.

Tanto a estrutura normativa hierárquica da sexualidade "cientificizada", quanto a estrutura hierárquica da heterossexualidade segundo a qual os homens oprimem as mulheres produzem normas de gênero. Isso porque se o gênero é uma forma de manifestação normativa da "sexualização da desigualdade", então o gênero é mero efeito da desigualdade precedente e absoluta dos gêneros. Entretanto, retorna o problema da ontologização de certos discursos que tendem a colocar certas questões naturalizadas da biologia como "fundamentais" nas discussões de gênero.

O problema de se basear nestes códigos pautados em visões sexualizadas do gênero é que isso reforça os processos de normalização, conforme evidenciado. Se o gênero é produzido numa cena de subordinação,

(...) o assédio sexual é o momento explícito de instituição da subordinação heterossexual. Efetivamente, isso significa que o assédio sexual se torna a alegoria da produção de gênero. A meu ver, os códigos de assédio sexual se tornam instrumentos pelos quais o gênero é assim reproduzido ${ }^{40}$.

Em outras palavras, pode-se dizer que sempre que certas transgressões normativas se pautam em discursos que tentam constituir transgressões específicas em sujeitos detentores de características essenciais passíveis de serem representadas e normatizadas dentro de um sistema político, institucionalizado e hierarquizado, a tendência é que as normas se tornem cada vez mais veladas e absolutas. Se determinadas regulações operam quando são

\footnotetext{
${ }^{39}$ BUTLER, Judith. Regulações de gênero. Sem página.

${ }^{40}$ BUTLER, Judith. Regulações de gênero. Sem página.
} 
MORAIS, Ricardo Manoel de Oliveira. Norma, gênero e representatividade: um estudo a partir do pensamento de Judith Butler. Revista Eletrônica Direito e Política, Programa de Pós-Graduação Stricto Sensu em Ciência Jurídica da UNIVALI, Itajaí, v.10, n.3, 2ㅇ quadrimestre de 2015. Disponível em: www.univali.br/direitoepolitica - ISSN 1980-7791

constatadas "transgressões de gênero" (como as cirurgias de correção de sexo, a patologização e criminalização psiquiátrica das distorções de gênero), a proibição do assédio sexual do "sujeito mulher" pelo "sujeito homem" baseia-se numa subordinação heterossexual como cena exclusiva do gênero, o que torna a norma "(...) o meio regulador de produção e manutenção das normas de gênero restritas à heterossexualidade" ${ }^{41}$.

Sendo as regulações normativas o que constrói regularidades, tanto pela via de disciplinas e vigilâncias por meio de estruturas jurídicas de exercício de poder, quanto por vias produtivas, pode-se dizer que quando " $(.$.$) as regulações$ operam através de normas, elas se tornam momentos chave nos quais a idealidade da norma é reconstituída, e sua historicidade e vulnerabilidade são temporariamente excluídas" ${ }^{\prime 2}$. Nesse sentido, ainda que as regulações possuam formas jurídicas e legais, elas não se resumem a elas. As normas podem ser, inclusive, definidas como categorias que tornam os indivíduos intercambiáveis uns com os outros, vinculando processos de assujeitamento.

Tais processos, pela sutileza com que são instaurados socialmente e por estarem legitimados por discursos de verdade, veiculam regulamentações com alto grau de aceitação. Entretanto, caso certos indivíduos, marcados pela violência normativa, transgridam a norma, surgem processos que tentam absorvê-los nos sistemas de poder, constituindo as transgressões de outrora como os sujeitos do agora, reforçando a universalidade normativa.

Se por um lado as normas violentam, por outro elas produzem sujeitos e tentam abarcá-los em sistemas institucionais, de modo que elas continuem a ser aceitas como universais, reforçando sua aparência de preponderância hegemônica ${ }^{43}$. Logo, certas transgressões normativas, por mais "emancipatórias" que sejam, correm o risco de serem encampadas pelo poder normalizador que, reconhecendo estas transgressões nos sistemas políticos e criando outros

\footnotetext{
${ }^{41}$ BUTLER, Judith. Regulações de gênero. Sem página.

${ }^{42}$ BUTLER, Judith. Regulações de gênero. Sem página.

43 BUTLER, Judith. Regulações de gênero. Sem página.
} 
MORAIS, Ricardo Manoel de Oliveira. Norma, gênero e representatividade: um estudo a partir do pensamento de Judith Butler. Revista Eletrônica Direito e Política, Programa de Pós-Graduação Stricto Sensu em Ciência Jurídica da UNIVALI, Itajaí, v.10, n.3, 2ㅇ quadrimestre de 2015. Disponível em: www.univali.br/direitoepolitica - ISSN 1980-7791

"anormais" que não são abarcados por esta constituição subjetiva específica. Assim, a construção de pessoas é feita de acordo com normas abstratas que condicionam e excedem as vidas que fabricam.

\section{O SUJEITO CONSTITUÍdO: CONDIÇÃO DE POSSIBILIDADE PARA A REPRESENTATIVIDADE}

Em Problemas de gênero, Butler tece considerações acerca da constituição normativa de sujeitos e o modo como o modelo representativo se fortalece enquanto norma com isso. Ao pensar o problema do gênero como norma, tem-se que a norma é mais que repressão. $O$ poder que opera nesta estrutura binária onde se pensa o gênero como espécie de configuração que constrói tanto o sujeito quanto o outro. A estabilidade interna presente neste tipo de análise é justamente a artificialidade gerada pela aparência de verdade que certos regimes epistemológicos naturalizam na presunção da heterossexualidade. Sendo estes discursos desmascarados, fica explicitado o caráter reificador destas características ontológicas ${ }^{44}$.

Butler, ao se interrogar sobre a melhor forma de examinar este sistema epistemológico e problematizar esta hierarquia sexual compulsória, diz que esta via não pode jamais constituir um outro subjetivado, que irá fazer frente à esta hierarquia de sexo já subjetivada. A questão é muito mais de desconstituir e desestabilizar as distinções entre o natural (sexo) e o artificial (gênero) que operam nas normas de gênero. Não se trata de estabelecer uma identidade subjetivada para os indivíduos que, de alguma, não se adéquam aos regulamentos binários de sexo, mas de desconstruir a aparente naturalidade nos discursos de gênero.

Para explicitar a ausência radical de sentido nas categorias de sexo, gênero e desejo, Foucault, reformulando Nietzsche, propôs como forma de investigação a

\footnotetext{
${ }^{44}$ BUTLER, Judith. Problemas de gênero: feminismo e subversão de identidade. Tradução de Renato Aguiar. Rio de Janeiro: Civilização Brasileira, 2003.
} 
MORAIS, Ricardo Manoel de Oliveira. Norma, gênero e representatividade: um estudo a partir do pensamento de Judith Butler. Revista Eletrônica Direito e Política, Programa de Pós-Graduação Stricto Sensu em Ciência Jurídica da UNIVALI, Itajaí, v.10, n.3, 2ㅇ quadrimestre de 2015. Disponível em: www.univali.br/direitoepolitica - ISSN 1980-7791

já mencionada genealogia ${ }^{45}$. Esta analítica, ao se recusar buscar as origens do gênero, do desejo, de uma identidade sexual ontológica que a "repressão" impede as pessoas de verem e serem,

(...) investiga as apostas políticas, designando como origem e causa categorias de identidade que, na verdade, são efeitos de instituições, práticas e discursos cujos pontos de origem são múltiplos e difusos. A tarefa dessa investigação é centrar-se - e descentrar-se - nessas instituições definidoras: 0 falocentrismo e a heterossexualidade compulsória ${ }^{46}$.

Nessa perspectiva, tendo em vista que a genealogia nega os universais ontológicos que existem acerca de elementos como a norma, o gênero, o sexo, o desejo humano, o conhecimento, uma investigação genealógica analisa mais a instabilidade das ontologias e menos o seu momento de "origem". Assim, Butler sustenta que certas teorias feministas, ao tentar resolver as questões de identidade primária para dar cabo à sua tarefa política, assumem um paradigma problemático, colocando a "mulher" como o sujeito político a ser representado nas categorias normativas.

Se, por um lado, certos discursos psicanalíticos assumem a estrutura heterossexual como regime epistemológico, pensando a homossexualidade como invariante associada a formas de ininteligibilidade cultural, por outro lado, pensar a categoria da "mulher" como um sujeito universalmente representável é, da mesma forma, reforçar as normas, visando inserir este sujeito no âmbito normativo. Para Butler, a teoria feminista presume que existe uma identidade definida da "mulher".

Mas política e representação são termos polêmicos. Por um lado, a representação serve como termo operacional no seio de um processo político que busca estender visibilidade e legitimidade às mulheres como sujeitos políticos; por outro lado, a representação é a função normativa de uma linguagem que revelaria ou distorceria o que é tido como verdadeiro sobre a categoria das mulheres. Para a teoria

\footnotetext{
${ }^{45}$ FOUCAULT, Michel. A Verdade e as Formas Jurídicas. Tradução de Roberto Cabral de Melo Machado e Eduardo Jardim Morais. $3^{a}$ ed. Rio de Janeiro: NAU Editora, 2002.
}

${ }^{46}$ BUTLER, Judith. Problemas de gênero: feminismo e subversão de identidade. p. 9. 
MORAIS, Ricardo Manoel de Oliveira. Norma, gênero e representatividade: um estudo a partir do pensamento de Judith Butler. Revista Eletrônica Direito e Política, Programa de Pós-Graduação Stricto Sensu em Ciência Jurídica da UNIVALI, Itajaí, v.10, n.3, 2ㅇ quadrimestre de 2015. Disponível em: www.univali.br/direitoepolitica - ISSN 1980-7791

feminista, o desenvolvimento de uma linguagem capaz de
representá-las completa ou adequadamente pareceu
necessário, a fim de promover a visibilidade política das
mulheres. Isso parecia obviamente importante,
considerando a condição cultural difusa na qual a vida das
mulheres era mal representada ou simplesmente não
representada 47 Mas, na medida em que a noção de um "sujeito mulher" é questionável, pois certas singularidades não são estáveis ou permanentes, muito se questiona acerca da viabilidade de colocar o "sujeito" como candidato último à representação. Isso porque a "representação política" estabelece a priori que o critério para que se seja representável é a definição de características reconhecíveis naqueles sujeitos que se pretende representar. "Em outras palavras, as qualificações do ser sujeito têm que ser atendidas para que a representação possa ser expandida"48.

Porém, Butler observa que os sistemas políticos produzem as subjetividades para, em seguida, instituir os mecanismos de representação. Ou seja, estes procedimentos regulamentares, condições de possibilidade para a representação, colocam os indivíduos numa estrutura de poder e, "(...) em virtude de a elas estarem condicionados, os sujeitos regulados por tais estruturas são formados, definidos e reproduzidos de acordo com as exigências delas" ${ }^{\prime 49}$.

Dessa forma, as estruturas jurídicas representam as mulheres como um sujeito universal feminista, efeito da artificialidade representacional. O "sujeito feminista" se revela discursivamente constituído. Neste panorama, o apelo acrítico a esse sistema em nome da emancipação das "mulheres" estaria fadado ao fracasso, pois os sujeitos que são produzidos politicamente são, invariavelmente, produzidos por meio de práticas de exclusão que não aparecem $^{50}$.

\footnotetext{
${ }^{47}$ BUTLER, Judith. Problemas de gênero: feminismo e subversão de identidade. p.18.

${ }^{48}$ BUTLER, Judith. Problemas de gênero: feminismo e subversão de identidade. p.18.

${ }^{49}$ BUTLER, Judith. Problemas de gênero: feminismo e subversão de identidade. p.18.

${ }^{50}$ Cf. BUTLER, Judith. Problemas de gênero: feminismo e subversão de identidade. p. 20
} 
MORAIS, Ricardo Manoel de Oliveira. Norma, gênero e representatividade: um estudo a partir do pensamento de Judith Butler. Revista Eletrônica Direito e Política, Programa de Pós-Graduação Stricto Sensu em Ciência Jurídica da UNIVALI, Itajaí, v.10, n.3, 2ㅇ quadrimestre de 2015. Disponível em: www.univali.br/direitoepolitica - ISSN 1980-7791

Na medida em que uma determinada estrutura política propicia o canal político representativo para que se represente o "sujeito feminista", todas as demais singularidades que não se encontram circunscritas neste "sujeito mulher", segundo Butler, estariam excluídas, tanto da norma quanto da representação. Este "excluído" irá se assujeitar mediante procedimentos regulamentares que o violentarão, valendo relembrar das crianças intersexuais submetidas a cirurgias "corretivas". Pode-se dizer que a lei produz e oculta o sujeito, invocando como premissa a própria hegemonia reguladora da lei. Nesse sentido,

Não basta inquirir como as mulheres podem se fazer representar mais plenamente na linguagem e na política. A crítica feminista também deve compreender como a categoria das "mulheres", o sujeito do feminismo, é produzida e reprimida pelas mesmas estruturas de poder por intermédio das quais busca-se a emancipação ${ }^{51}$.

A mulher colocada como sujeito, levando-se em consideração tudo o que este tipo de categoria normativa suscita, deve ser, igualmente, problematizada. Se um sujeito é constituído pela norma, que se pauta num fundamento fictício decorrente da reivindicação por legitimidade, ainda assim prevalece a integridade ontológica de um sujeito perante a lei em detrimento de outras singularidades, não representáveis.

A hipótese prevalecente da integridade ontológica do sujeito perante a lei pode ser vista como o vestígio contemporâneo da hipótese do estado natural, essa fábula fundante que é constitutiva das estruturas jurídicas do liberalismo clássico. A invocação performativa de um "antes" não histórico tornase a premissa básica a garantir uma ontologia pré-social de pessoas que consentem livremente em ser governadas, constituindo assim a legitimidade do contrato social ${ }^{52}$.

A suposição de que existe uma identidade comum de mulher é um problema político para além das ficções fundacionais que sustentam a noção de sujeito. Se alguém é "mulher", isso, com certeza, não é tudo o que esse alguém é, ou seja, o termo não é exaustivo. Nessa perspectiva, a noção de "gênero" parece ter

\footnotetext{
${ }^{51}$ BUTLER, Judith. Problemas de gênero: feminismo e subversão de identidade. p.19.

52 BUTLER, Judith. Problemas de gênero: feminismo e subversão de identidade. p.19-20.
} 
MORAIS, Ricardo Manoel de Oliveira. Norma, gênero e representatividade: um estudo a partir do pensamento de Judith Butler. Revista Eletrônica Direito e Política, Programa de Pós-Graduação Stricto Sensu em Ciência Jurídica da UNIVALI, Itajaí, v.10, n.3, 2ㅇ quadrimestre de 2015. Disponível em: www.univali.br/direitoepolitica - ISSN 1980-7791

tornado impossível separar a noção de gênero das interseções político-cultural onde ele é produzido e mantido ${ }^{53}$. Se há a presunção política de que há uma base universal para o feminismo (ou para toda reivindicação política emancipatória), vale dizer que a este aparato ontológico acompanha a crença de que a opressão das mulheres possui uma forma singular, discernível na estrutura de dominação hegemônica, patriarcal ou masculina. Entretanto, "A noção de um patriarcado universal tem sido amplamente criticada (...) por seu fracasso em explicar os mecanismos da opressão de gênero nos contextos culturais concretos em que ela existe ${ }^{\prime \prime 5}$.

Esta forma de teorização subjetivante no sentido de conferir um status universal ao "patriarcado", de modo a fortalecer a representatividade do feminismo, motivou ocasionalmente um atalho na direção de universalizar uma categoria fictícia da estrutura de dominação, tida como responsável pela produção de uma experiência universalmente comum de subjugação das mulheres. Mas,

(...) existiriam traços comuns entre as "mulheres", preexistentes à sua opressão, ou estariam as "mulheres" ligadas em virtude somente de sua opressão? Há uma especificidade das culturas das mulheres, independente de sua subordinação pelas culturas masculinistas hegemônicas? Caracterizam-se sempre a especificidade e a integridade das práticas culturais ou linguísticas das mulheres por oposição e, portanto, nos termos de alguma outra formação cultural dominante? Existe uma região do "especificamente feminino", diferenciada do masculino como tal e reconhecível em sua diferença por uma universalidade indistinta e consequentemente presumida das "mulheres"? 55 .

Pode-se dizer que Butler critica, em grande medida, esta "ontologicização" dos sujeitos, denunciando a imposição de um sujeito estável até mesmo nos grupos que nascem como resistência aos modelos hegemônicos.

\footnotetext{
${ }^{53}$ Cf. DÍAZ, Elvira Burgos. Desconstrução e subversão: Judith Butler. Sapere Aude, Belo Horizonte, V.4 - $\quad$ n.7, 2013. http://periodicos.pucminas.br/index.php/SapereAude/article/viewFile/5543/5507. Acesso em 6 de junho de 2015. p.5.
}

${ }^{54}$ BUTLER, Judith. Problemas de gênero: feminismo e subversão de identidade. p. 20.

${ }^{55}$ BUTLER, Judith. Problemas de gênero: feminismo e subversão de identidade. p. 21. 
MORAIS, Ricardo Manoel de Oliveira. Norma, gênero e representatividade: um estudo a partir do pensamento de Judith Butler. Revista Eletrônica Direito e Política, Programa de Pós-Graduação Stricto Sensu em Ciência Jurídica da UNIVALI, Itajaí, v.10, n.3, 2ㅇ quadrimestre de 2015. Disponível em: www.univali.br/direitoepolitica - ISSN 1980-7791

\section{CONSIDERAÇÕES FINAIS}

A suposta universalidade/unidade/ontologia do sujeito do feminismo seria, para Butler, minada pela restrição do discurso representacional em que funciona. A insistência prematura num sujeito estável (compreendido como uma categoria una), gera inúmeras recusas em aceitar esta categoria. Isso porque a criação de um universalismo, na medida em que implica exclusões (voluntárias, para quem não se sente contemplado; compulsórias, para quem não se encaixa nestas categorias), revela consequências coercitivas e reguladoras, mesmo que a elaboração vise a emancipação. "Não há dúvida, a fragmentação no interior do feminismo e a oposição paradoxal ao feminismo - por parte de "mulheres" que o feminismo afirma representar - sugerem os limites necessários da política da identidade ${ }^{\prime \prime 56}$.

Evidente que não se trata de recusar a política representacional, o que, evidentemente, não é possível. Na medida em que as estruturas jurídicas da linguagem, da política e do saber constituem o campo contemporâneo de poder (uma vez que não há oposição fora do poder), a crítica deve ser interna, através de uma genealogia crítica da norma. "E a tarefa é justamente formular, no interior dessa estrutura constituída, uma crítica às categorias de identidade que as estruturas jurídicas contemporâneas engendram, naturalizam e imobilizam" ${ }^{57}$.

Para tanto, é necessário repensar as construções ontológicas da identidade na prática política representacional. Assim,

(...) é tempo de empreender uma crítica radical, que busque libertar a teoria feminista da necessidade de construir uma base única e permanente, invariavelmente contestada pelas posições de identidade ou anti-identidade que o feminismo invariavelmente exclui ${ }^{58}$.

Recolocar a questão da representação sob um viés outro que não o da constituição de sujeitos normativos parece ser, efetivamente, o grande desafio. E

\footnotetext{
56 BUTLER, Judith. Problemas de gênero: feminismo e subversão de identidade. p.22.

57 BUTLER, Judith. Problemas de gênero: feminismo e subversão de identidade. p.22.

58 BUTLER, Judith. Problemas de gênero: feminismo e subversão de identidade. p.23.
} 
MORAIS, Ricardo Manoel de Oliveira. Norma, gênero e representatividade: um estudo a partir do pensamento de Judith Butler. Revista Eletrônica Direito e Política, Programa de Pós-Graduação Stricto Sensu em Ciência Jurídica da UNIVALI, Itajaí, v.10, n.3, 2ㅇ quadrimestre de 2015. Disponível em: www.univali.br/direitoepolitica - ISSN 1980-7791

é justamente por isso que se deve pensar a noção de gênero como norma, para que seja possível a denúncia da artificialidade deste sistema, de modo a possibilitar não uma ontologia de sujeitos, mas uma forma de resistir no tempode-agora ${ }^{59}$. A política representativa não deve ser tomada como estável, somente sendo possível representar sujeitos essencialmente constituídos ${ }^{60}$. Uma proposta outra em relação a isso é problematizar todo o tipo de norma numa precisão temporal e social, passível de ser alterada por ações.

Foucault, nos Dits et Écrits, em Face aux gouvernements, les droits de I'homme e Inutile de se soulever?, reflete a este respeito ${ }^{61}$. Segundo ele, Se o século XIX é marcado pela emergência de direitos decorrentes de lutas sociais, como o direito de associar-se conquistado pelas lutas sindicais, o século XX é marcado por outro tipo de movimento, como o feminismo e o homoafetivo, cuja reivindicação vai além da questão de associar-se, tomando um caráter antidiscriminatório. Assim, se há o direito de escolha sexual para Focault, essa é a razão pela qual ele critica o direito natural, na medida em que tal noção universal remete a uma essência.

Nessa medida, Foucault defende a criação de um novo direito relacional, cujo escopo são novos valores, que possam ir além dos indivíduos concernidos por eles. Isso significa que não se trata de reintroduzir a homossexualidade na normalidade geral das relações sociais, mas de transformar as próprias relações chamadas normais. Tal direito das relações, dessa forma, implica em uma nova constituição normativa, alterando os efeitos de verdade de uma forma mais profunda que a mera "normalização da homoafetividade", por exemplo. Trata-se da possibilidade de fazer emergir o reconhecimento, no campo institucional, nas

\footnotetext{
${ }^{59}$ MATOS, Andityas Soares de Moura Costa. Filosofia Radical e Utopia: Inapropriabilidade, an-arquia, a-nomia. Rio de Janeiro: Via Verita, 2014. p.53.

${ }^{60}$ KORPI, Piia. The Notion of Gender as a Norm in Judith Butler's Thought. Pro gradu tutkielma 94s. Filosofia, $2009 . \quad$ Disponível https://tampub.uta.fi/bitstream/handle/10024/81277/gradu04062. pdf?sequence=1. Acesso em 6 de junho de 2015. p.29.

${ }^{61}$ FOUCAULT, Michel. Dits et Écrits (vol.1-4). Org. Daniel Defert e François Ewald. Paris: Gallimard, 1994.
} 
MORAIS, Ricardo Manoel de Oliveira. Norma, gênero e representatividade: um estudo a partir do pensamento de Judith Butler. Revista Eletrônica Direito e Política, Programa de Pós-Graduação Stricto Sensu em Ciência Jurídica da UNIVALI, Itajaí, v.10, n.3, 2quadrimestre de 2015. Disponível em: www.univali.br/direitoepolitica - ISSN 1980-7791

relações de indivíduo a indivíduo, mas que não passe, forçosamente, pela emergência de um grupo reconhecido.

\section{REFERÊNCIAS DAS FONTES CITADAS}

BUTLER, Judith. Problemas de gênero: feminismo e subversão de identidade. Tradução de Renato Aguiar. Rio de Janeiro: Civilização Brasileira, 2003.

BUTLER, Judith. Regulações de gênero. Cadernos Pagu, $n^{\circ} 42$, Campinas Jan./June 2014. Disponível em: http://www.scielo.br/scielo.php?pid=S0104$83332014000100249 \&$ script $=s c i \_a r t t e x t \& t \operatorname{lng}=e s \# f n 01$. Acesso em 6 de junho de 2015.

CANDIOTTO, Cesar. Foucault e a crítica da verdade. Belo Horizonte: Autêntica Editora; Curitiba: Champagnat, 2010.

CASTRO, Edgardo. Vocabulário de Foucault: um percurso pelos seus temas, conceitos e autores. Tradução de Ingrid Müller Xavier. Belo Horizonte: Autêntica Editora, 2009.

DELEUZE, Gilles. Qu'est-ce qu'un dispositive?. In. Michel Foucault philosophe: Rencontre international. Paris 9, 10, II janvier 1988. Seuil/Gallimard, 1989. DÍAZ, Elvira Burgos. Desconstrução e subversão: Judith Butler. Sapere Aude, Belo Horizonte, v.4 - n.7, 2013. Disponível em http://periodicos.pucminas.br/index.php/SapereAude/article/viewFile/5543/5507 . Acesso em 6 de junho de 2015.

EWALD, François. Foucault a norma e o direito. Tradução de Antônio Fernando Cascais. Lisboa: Veja, 1993.

FONSECA, Márcio Alves. Michel Foucault e o Direito. São Paulo: Max Limonad, 2002.

FOUCAULT, Michel. A Verdade e as Formas Jurídicas. Tradução de Roberto Cabral de Melo Machado e Eduardo Jardim Morais. 3a ed. Rio de Janeiro: NAU Editora, 2002. 
MORAIS, Ricardo Manoel de Oliveira. Norma, gênero e representatividade: um estudo a partir do pensamento de Judith Butler. Revista Eletrônica Direito e Política, Programa de Pós-Graduação Stricto Sensu em Ciência Jurídica da UNIVALI, Itajaí, v.10, n.3, 2quadrimestre de 2015. Disponível em: www.univali.br/direitoepolitica - ISSN 1980-7791

Dits et Écrits (vol.1-4). Org. Daniel Defert e François Ewald. Paris: Gallimard, 1994.

. Em Defesa da Sociedade. Tradução de Maria Ermantina Galvão. São Paulo: Martins Fontes, 1999.

História da sexualidade I: A vontade de saber. Tradução de Maria Thereza da Costa Albuquerque e J. A Guilhon Albuquerque. Rio de Janeiro: Graal, 1988.

Leçons sur la volonté de savoir. Édition établie sous la direction de François Ewald et Alessandro Fontana, par Daniel Defert. Seuil/Gallimard: 2011.

Os anormais. Tradução de Eduardo Brandão. São Paulo: Martins Fontes, 2001.

KORPI, Piia. The Notion of Gender as a Norm in Judith Butler's Thought. Pro gradu - tutkielma 94s. Filosofia, 2009. Disponível em https://tampub.uta.fi/bitstream/handle/10024/81277/gradu04062.pdf?sequence $=1$. Acesso em 6 de junho de 2015.

LEGRAND, Stéphane, Les normes chez Foucault. Paris: Presses universitaires de France, 2007.

MACHEREY, Pierre. De Canguilhem à Foucault: la force des normes. Paris: La Fabrique éditions, 2009.

MATOS, Andityas Soares de Moura Costa. Filosofia Radical e Utopia: Inapropriabilidade, an-arquia, a-nomia. Rio de Janeiro: Via Verita, 2014. 